\title{
Estimation of reservoir properties from well logs and core plugs to reduce uncertainty in formation evaluation: a case study from the Kohat-Potwar Geologic Province
}

\author{
${ }^{1}$ Institute of Geology, University of the Punjab, Lahore 54590, Pakistan; *Corresponding author, E-mail: perveiz.geo@pu.edu.pk \\ ${ }^{2}$ Department of Computer Science and IT, The Islamia University of Bahawalpur, Pakistan
}

(Received: June 22, 2016; Revised accepted: February 26, 2018)

http://dx.doi.org/10.18814/epiiugs/2018/v41i1/018006

Formation evaluation and rock physics are powerful techniques to link the physical properties of rocks and pore fluids measured at boreholes with petrophysical, elastic, and seismic properties at boreholes or faraway from boreholes. However, several sources of uncertainty in the measurements of these properties can affect the strength of this link. A complete statistical workflow is proposed for obtaining petrophysical properties such as porosity, permeability, volume of shale, and water saturation at the well location. This workflow is based on the wireline logs and core plugs and is applied on the lower Jurassic siliciclastic reservoirs of Kohat-Potwar Geologic Province, Pakistan to determine its applicability, the advantages of the new integrated approach, and the value of uncertainty analysis. The linear regression relations are developed between several petrophysically derived parameters measured from core samples and calculated from well logs data. All these parameters are then used as input constraints in rock physics modeling to calculate seismic properties such as bulk and shear moduli, compressional and shear wave velocities etc. A linear relationship is established between porosity and seismic velocities obtained from rock physics model. The well logs predicted rock physics properties such as seismic (P and $S$-wave) velocities, effective densities and elastic moduli are in close agreement to those measured by using rock physics analysis. Statistical regression analysis revealed significant similarity in the porosity values obtained from geophysical well logs and core samples. The permeability of reservoir intervals show fairly strong linear relationship with the porosity, indicating that the reservoir interval of Datta sandstone is highly permeable and porous thus having large potential of hydrocarbon accumulation and production.

\section{Introduction}

Understanding and precise measurement of key reservoir properties like lithology, porosity, volume of shale, water saturation, permeability is primary goal of formation evaluation and reservoir estimation in petroleum industry. Generally it is assumed that the reservoir sand interval is homogeneous on some certain scale. However, on one hand, several forms of heterogeneity in reservoir parameters are present on different scales (Mavko et al., 2009). On other hand, the interaction between porous rocks and pore fluid also affect the petrophysical properties of reservoir rocks (Batzle and Wang, 1992; Khalid et al., 2014). Therefore, well understanding of the form and spatial distribution of these heterogeneities, the rock-fluid interaction and prediction of their impact on reservoir character is of great importance. Various theoretical models and empirical relationships have been suggested to map the rock-fluid interaction in reservoir rocks to delineate lithologies, fluid type and composition (Gassmann, 1951; Kuster and Toksöz, 1974; Brown and Korringa, 1975; Han et al., 1986; Tao and King, 1993; Gist, 1994; Gupta et al., 2012; Khalid and Ghazi, 2013; Khalid et al., 2014). However, most of these rock physics models have some limitations, thus can be valid and applied under certain checks and have need of some sort of specific properties as a feed which are not easily available or extracted from other geophysical data such as from wireline logs. As an example Gassmann (1951) model of homogeneous mineral modulus does not consider the pore geometry and valid only at low frequencies. Kuster and Toksöz (1974) model is valid under the assumption of isotropic and linear porous media. Brown and Korringa's model (1975) does not describe the ultrasonic lab conditions very well. Han's relations (Han et al., 1986) are dependent on confining pressure and fairly stable above $10 \mathrm{MPa}$. Therefore, the prediction of reservoir parameters and their accurate estimation from well logs is one of the central questions to geoscientists.

Most of the sand reservoirs have single porosity system of relatively homogeneous lithology on macro-scale. However, on micro-scale reservoir properties are heterogeneous (Barton et al., 2004; Mavko et al., 2009). This heterogeneity outcomes from physical and chemical reorganization processes over time, which complicates the reservoir characterization. Thus, the resulting reservoir properties incline to dif- 
fer as a function of spatial localities vertically and laterally. These heterogeneities result in large uncertainty in the reservoir properties estimated by different methods.

The derivation of peterphysical parameters is an inverse problem which requires an integrated approach. The solution of an inverse problem is not limited to a deterministic estimation of the solution which is supposed to be optimal in terms of best-fitting of the given dataset, but it also include the evaluation of the uncertainty of the inversion results. The improvement in reservoir characterization is very important to minimize the risk of drilled dry holes (Han and Batzle, 2002). This improvement is by the combine effort of wireline logs and core data with quantitative interpretation of wireline log data (Grana et al., 2012). The porosity, volume of shale, water saturation and hydrocarbon saturation are the main results obtained from the quantitative interpretation of geophysical well logs such as resistivity, gamma ray (GR), acoustic, density and neutron. Although several improved approaches along with optimized sets of equations exist to estimate these measurements (Fylling, 2002; Heidari et al., 2010), however, some uncertainty in the inferred parameters is always present because small error in any measurement may produce uncertainty in the final output (Fylling, 2002; Viberti, 2010). Theoretical models used to determine petrophysical properties may also produce the uncertainty in the final values. Thus, a statistical analysis is performed to establish the reliability in the obtained results.

Relationship between petrophysical properties and rock physics parameters of a reservoir rock are well established (Wyllie et al., 1956;
Domenico, 1984; Winkler and Murphy, 1995; Mavko et al., 2009). Rock physics modeling is a helping tool mainly used to build up a relationship between petrophysical parameters estimated from well logs and core data, and seismic parameters of fluid (brine/hydrocarbon) saturated rocks. The uncertainty and percentage error in formation evaluation and reservoir rock properties is penetrated through the well-calibrated rock physics model, used to link petrophysical properties with seismic properties of reservoir rock. Mukerji et al. (2001a) gave the concept of statistical rock physics.. Generally, in rock physics modeling a set of well-defined relationships are used that can translate petrophysical parameters into seismic properties. Fluid substitution is an important part of rock physics modeling, which make easy to differentiate reservoir fluids nature and its quantity in porous rock. Various kind of fluid substitution models are in practice (Mavko et al., 2009) to describe the relationship between the bulk modulus of the fluid-saturated rock $\left(K_{\text {sat }}\right)$, the modulus of rock-forming minerals $\left(K_{m}\right)$, the bulk modulus of the drained (or dry) rock $\left(K_{d r y}\right)$, and to the adiabatic bulk modulus of fluid $\left(K_{f}\right)$ present with pore spaces. However, Gassmann (1951) fluid substitution model is generally used to express the relationship between all above mentioned parameters.

The main objectives of this work include determining the numerous reservoir properties and to reduce the percentage error and uncertainty related with various kinds of measurements in the two wells A and B in the western part of the Potwar Plateau of Pakistan (Fig. 1) where exact prediction of petrophysical parameters is a big issue because of very complex tectonic settings (Khalid et al., 2015). The

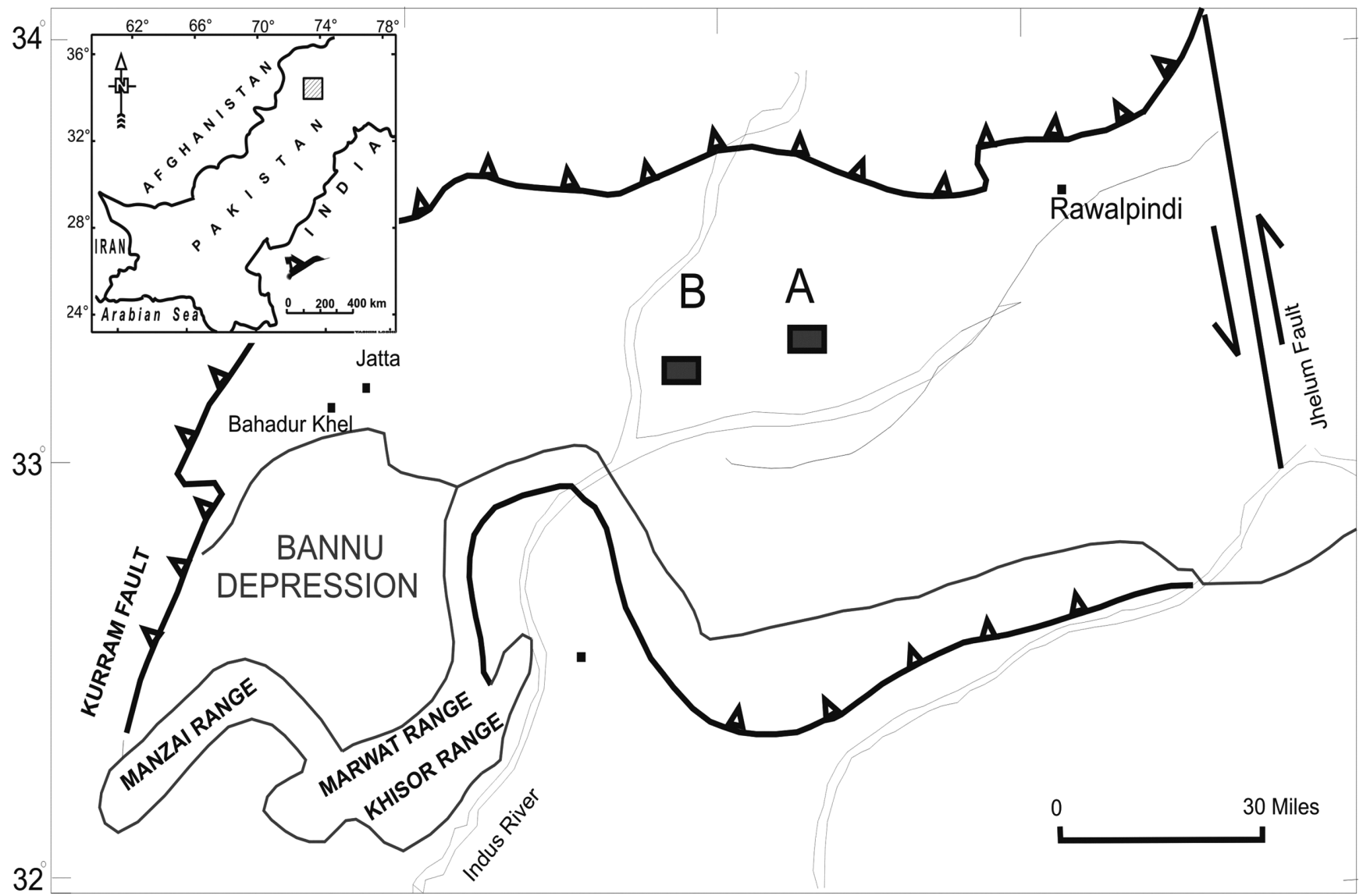

Figure 1. Location and geological map of the study area. A and B represent the well locations used in this study. 
main focus is the assessment of the percentage error and uncertainty in the estimation and calculation of each parameter to provide a reliable value of each parameter. The wireline log data will be compared with the core data to minimize the uncertainty and to enhance the accuracy in the measurements. This work covers the applications of basic procedure to find out petrophysically derived parameters and rock physics modeling to link these calculated parameters with physical properties of rock-fluid composite and the statistical approach to analyze the error. A simple and complete statistical workflow is proposed to correlate core plugs with wireline log data. Linear statistical relationships are developed and implied between numerous reservoir parameters to evaluate percentage error and uncertainty in the measurements of different quantities.

\section{Data and Method to Extract Reservoir Parameters from Core-log Integration}

All kind of wireline logs including gamma ray (GR), resistivity (LLD), sonic (DT), caliper, density (RHOB) and spontaneous potential (SP) logs run in both wells are used in this study. Total 44 core plug samples of well A taken in the interval of $4595 \mathrm{~m}$ to $4627 \mathrm{~m}$ and 53 of well B in the interval of $4705 \mathrm{~m}$ to $4760 \mathrm{~m}$ are also analyzed to measure uncertainty in petrophysical and rock physics parameters. The flow chart of the methodology is shown in Figure 2. In this work, we consider the case of consolidated or poorly consolidated siliciclastic rocks. Heterogeneity in rock composition, pore shapes, interbedded thin shale layers, effect of invasion, pore fluid types and saturation levels, fluids distribution pattern, cracks and their orientation, grain packing, pore networks and other chemical and physical properties of both fluids and solids, calibration issues etc. are possible sources of

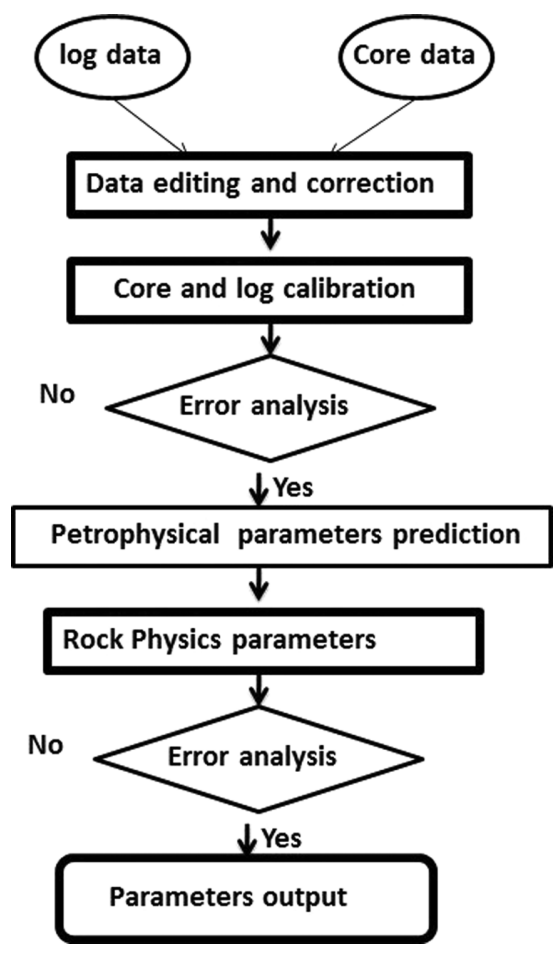

Figure 2. Flow chart of the methodology used in this study. uncertainty in peterophysical parameters and quantitative formation evaluation. It is difficult to draw a scale of effectiveness of the heterogeneity features. All features have their own significance and can influence the petrophyscial properties depending upon the area, geology, compaction, depositional environment etc. In shallow and soft reservoirs having high porosity, fluid saturations may have substantial effects on seismic and petrophysical paramters. To measure these uncertainties statistical regression analysis is also done. Crossplots among different petrophysical parameters were also prepared to verify log calculated values against those derived from core analysis.

\section{Peterophysical Parameters Measurements}

Volume of shale $\left(V_{s h}\right)$ is one of the most important pertophysical parameter, required to define reservoir quality as well as reservoir character. Shale volume was calculated to approximate clay contents in the reservoir rock. It may affect the water saturation in the reservoir. Gamma ray (GR) log was used to estimate $V_{s h}$. The volume of shale was also estimated by petrography of the core samples. The computation of porosity from log has need of lithological information, core data and laboratory analysis, such as the properties of the pore fluid and grain matrix. In next step, the porosity of reservoir interval is found and corrected by using density and neutron logs. These porosities are then compared to those measured from core plugs.

The water saturation $\left(S_{w}\right)$ measurements taken in open hole with resistivity logging are fundamental to quantify hydrocarbon saturation $\left(S_{h}\right)$, original oil in place (OOIP) or original gas in place (OGIP) volumes. In reservoir parameters estimation, the exact determination of $S_{w}$ with accuracy is very challenging because there are a number of factors that can affect the values of $S_{w}$ (Tiab and Donaldson, 2004; Ahmed et al., 2017). Several independent methods that can be used to estimate $S_{w}$ can lead to somewhat changed $S_{w}$ values that may liken to considerable differences in OOIP or OGIP volumes. Therefore, it is a big task to select an appropriate method to find out accurate value of $S_{w}$ and its distribution throughout the reservoir sand interval. Following equation proposed by Archie (Archie, 1942) is used to find out water saturation in clean sand intervals by using resistivity log:

$$
\begin{aligned}
& F=a / \phi^{m}, \\
& S_{w}=\left(\frac{a}{\phi^{m}} \frac{R_{w}}{R_{t}}\right)^{1 / n},
\end{aligned}
$$

where $F$ is formation resistivity factor $\left(F=R_{0} / R_{w}, R_{w}=\right.$ brine-water resistivity, and $R_{0}=$ rock resistivity with $S_{w}=1.0$ ), while $a, m$ and $n$ are cementation constant, the cementation exponent and saturation exponent respectively. In the above equation, $R_{t}$ is the true resistivity of formation at given fluid saturation. From Equation (2), it is clear that the water saturation $\left(S_{w}\right)$ is inversely proportional to true formation water resistivity $\left(R_{t}\right)$. Shaley rocks have lower values of $R_{t}$, therefore, the amount of $S_{w}$ increases with the increase of volume of shale $\left(V_{s h}\right)$. On the other hand, shale volume has inverse relation with formation resistivity factor $(F)$ and $S_{w}$ has direct relation with $F$ and increases with increase in $F$. 


\section{Relationship between Petrophysical and Rock Physics Parameters}

The algorithm of rock physics model starts with the determination of elastic moduli such as bulk and shear moduli of pore fluids and solid matrix, afterword, the elastic moduli of dry rock or rock frame are computed. Various models differ for the estimation of the dry rock moduli (Murphy et al., 1993; Pride et al., 2004; Zinsner, 2007). In this work, dry rock bulk and shear modulus of rock frame are estimated by using formula given by Murphy et al. (1993). Finally, Gassmann fluid substitution model (FSM) is used to quantify the effect of fluids present within reservoir pore spaces on porous rock properties. The Gassmann's relation for saturated bulk modulus in the simplest form is:

$$
K_{s a t}=K_{d r y}+\alpha^{2} M^{1},
$$

where $a$ is the Biot's coefficient (Biot, 1941) or also called coefficient of effective stress

$$
\alpha=1-K_{d r y} / K_{m},
$$

is always has numerical value less than 1 in real porous and permeable medium and it is a complex function of number of voids (porosity), pore geometry, clay content, grain size, mineralogical composition of rocks under study etc. (Hilterman, 2001; Mavko et al., 2009). The modulus

$$
M=\frac{\phi}{K_{f}}+\frac{\alpha-\phi}{K_{m}},
$$

is defined as the pressure needed to force fluid into formation without changing volume (Russell et al., 2003) and $f$ is rock porosity. The compressional wave velocity $\left(V_{P}\right)$ and shear wave velocity $\left(V_{S}\right)$ are found out by

$$
\begin{aligned}
& V_{P}=\left(\frac{K_{\text {sat }}+4 \mu / 3}{\rho_{\text {eff }}}\right)^{1 / 2}, \\
& V_{S}=\left(\frac{\mu}{\rho_{\text {eff }}}\right)^{1 / 2},
\end{aligned}
$$

where,

$$
\rho_{\text {eff }}=(1-\phi) \rho_{m}+\phi \rho_{f} .
$$

In the above equation, $\rho_{\text {eff }}$ is the effective rock density saturated with fluids, while $\rho_{m}$ and $\rho_{f}$ are being the rock forming mineral and pore fluid densities, respectively. If porous media contains more than one fluid or multi-phase fluid then the fluid modulus and density are equal to the arithmetic average of every single fluid phase (Khalid et al., 2014).

$$
\begin{aligned}
& K_{f}=\left[\sum_{k=1}^{m} \frac{S_{k}}{K_{k}}\right]^{-1}, \\
& \rho_{f}=\sum_{k=1}^{m} S_{k} \rho_{k},
\end{aligned}
$$

where $r$ and $S$ represent the density and saturation of the fluid phase denoted by sub index $k$ and $m$ which are the total number of fluid phases may present in pore spaces.

Similarly, $K_{\text {sat }}$ was calculated directly from sonic and density logs data by using following relation.

$$
K_{\text {sat }}=\rho_{\text {eff }}\left(V_{P}^{2}-4 / 3 V_{S}^{2}\right) .
$$

The results of FSM and wireline logs were compared. Statistical analysis is done to quantify the error and uncertainty.

\section{Quantitative Estimation of Petrophysical Parameters}

The above narrated quantitative work flow has been applied on two real data sets from two exploration wells, Western Potwar Plateau, Pakistan. Both wells were drilled vertically in a deep clastic reservoir of Jurassic age made by soft sandstones of a turbidite channel complex. The prospect is a typical structural with complete developed petroleum system (Khalid et al., 2015). The core analysis and petrophysical interpretation reveals that sparse shale beds are also present and the sandstone is composed by $60-70 \%$ quartz and remaining is clay and other minerals. The clay is a mixture of illite and kaolinite (respectively $60 \%$ and $40 \%$ ). The reservoir fluid is oil and brine. The determinations of reservoir quality and formation evaluation are mainly depending on the accuracy of quantitative evaluation of petrophysical parameters. The comprehensive set of wireline logs including GR, density, resistivity, sonic and neutron of high resolution is used to provide reliable formation evaluation. Globally, the quality of data is good (Fig. 3). Wireline logs and core data are combined together for quantitative formation evaluation. The qualitative identification of reservoir zones was made by the log signatures from shale beds and compact beds. Beds with high GR, high neutron values, low resistivity and low density values indicated shale and were thus eliminated. The quantitative identification of the reservoir zones was done by volume of shale and clay, porosity and fluid content determinations through the use of empirical relationships already mentioned in previous section.

\section{Volume of Shale}

At first step, the gross lithological facies were marked by using GR and SP logs. These lithologies were confirmed through other logs such as resistivity, sonic, and density-neutron. After confirmation of lithologies the volume of shale $\left(V_{\mathrm{sh}}\right)$ was computed from GR log using gamma ray index $\left(I_{G R}\right)$ with the help of Clavier (Clavier et al., 1977), Stieber (Stieber, 1970), and Larionov (Larionov, 1969) equations. The volume of shale computed via the equations proposed by Clavier, Stieber and Larionov in the intervals of Datta sandstone encountered in wells A and B is plotted in Figures $4 \mathrm{a}$ and $\mathrm{b}$. The values of $V_{s h}$ computed by the above mentioned equations are in close agreement, especially at lower values of $I_{G R}$. However, $V_{s h}$ by Clavier and Larionov are closely matched in the whole interval of $I_{G R}$ in both wells. The relative error in $V_{s h}$ by Clavier and Stieber is upto $15 \%$ for large values of $V_{s h}\left(V_{s h}>50 \%\right)$. The mean values of $V_{s h}$ in well A and well B are completely overlaps for all values of $I_{G R}$ (Fig. 4c). The relationship between $V_{s h}$ and $I_{G R}$ is determined using a non-linear regression with regression coefficient $\mathrm{R}^{2} \sim 0.999$. The average value of $V_{\text {sh }}$ in the zone is $14-18 \%$ in well A whereas in well $\mathrm{B}$, it is much lower (6-8\%), which shows that the reservoir in well B is clean sand whereas in well A it is with shaly sand beds. The petrographic analysis done by using XRD of core samples confirms these values. The average volume of shale in well B is sufficient low to allow for free fluid flow. 

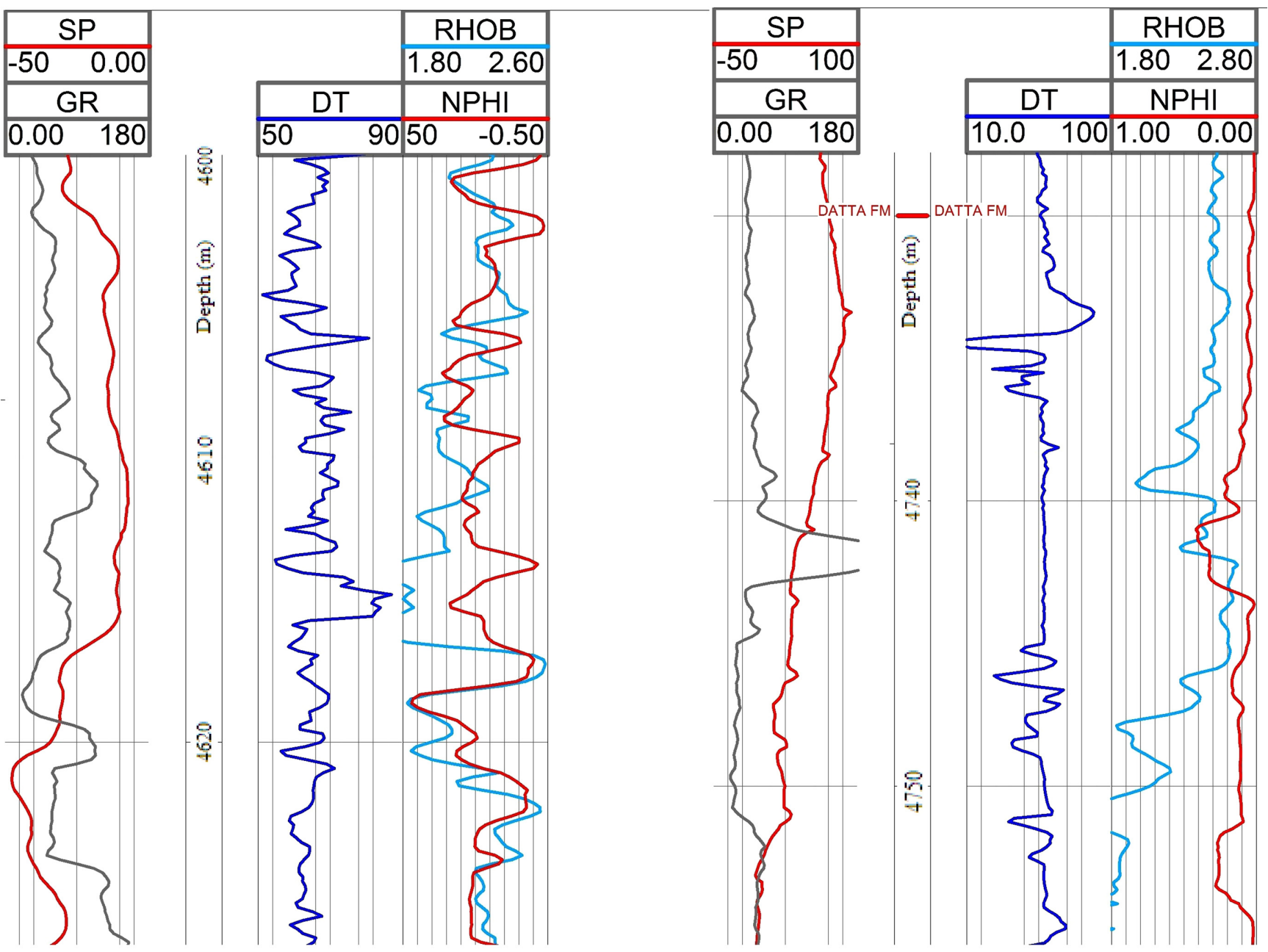

Figure 3. Wireline logs of well $A$ and well $B$ showing the quality of sand reservoir.
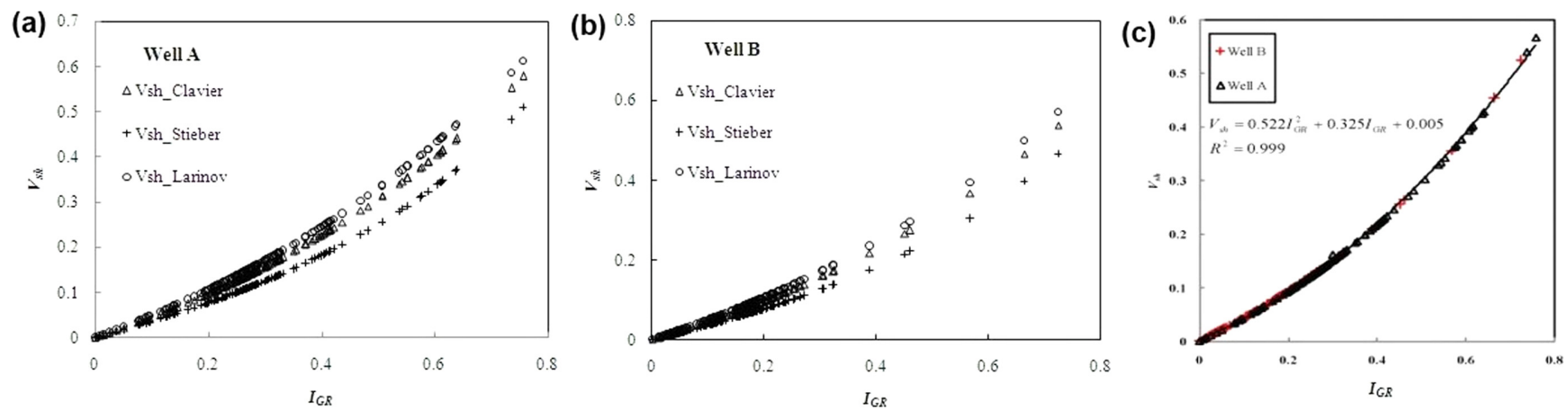

Figure 4. Crossplot between gamma ray index (IGR) and volume of shale $\left(V_{\text {sh }}\right)$ in well $A(a)$ and well $B$ (b) computed by using various relationships. (c) Mean values of $V_{\text {sh }}$ in wells $A$ and $B$.

\section{Porosity and Permeability}

The Dresser Atlas (1979) proposed relationships to find out porosity were used and the calculated porosity was corrected from density and neutron logs. The porosity measured from core samples and core density and $\log$ porosity and $\log$ density are plotted in Figures $5 \mathrm{a}$ and $\mathrm{b}$ along with their regression relations. The porosities in both wells vary in a large interval. A linear regression is developed to determine the correlation between porosity and density by geostatistical technique.

$$
\rho=-m \phi+c,
$$

where $r$ is the formation bulk density, $m$ and $c$ are the coefficients to 

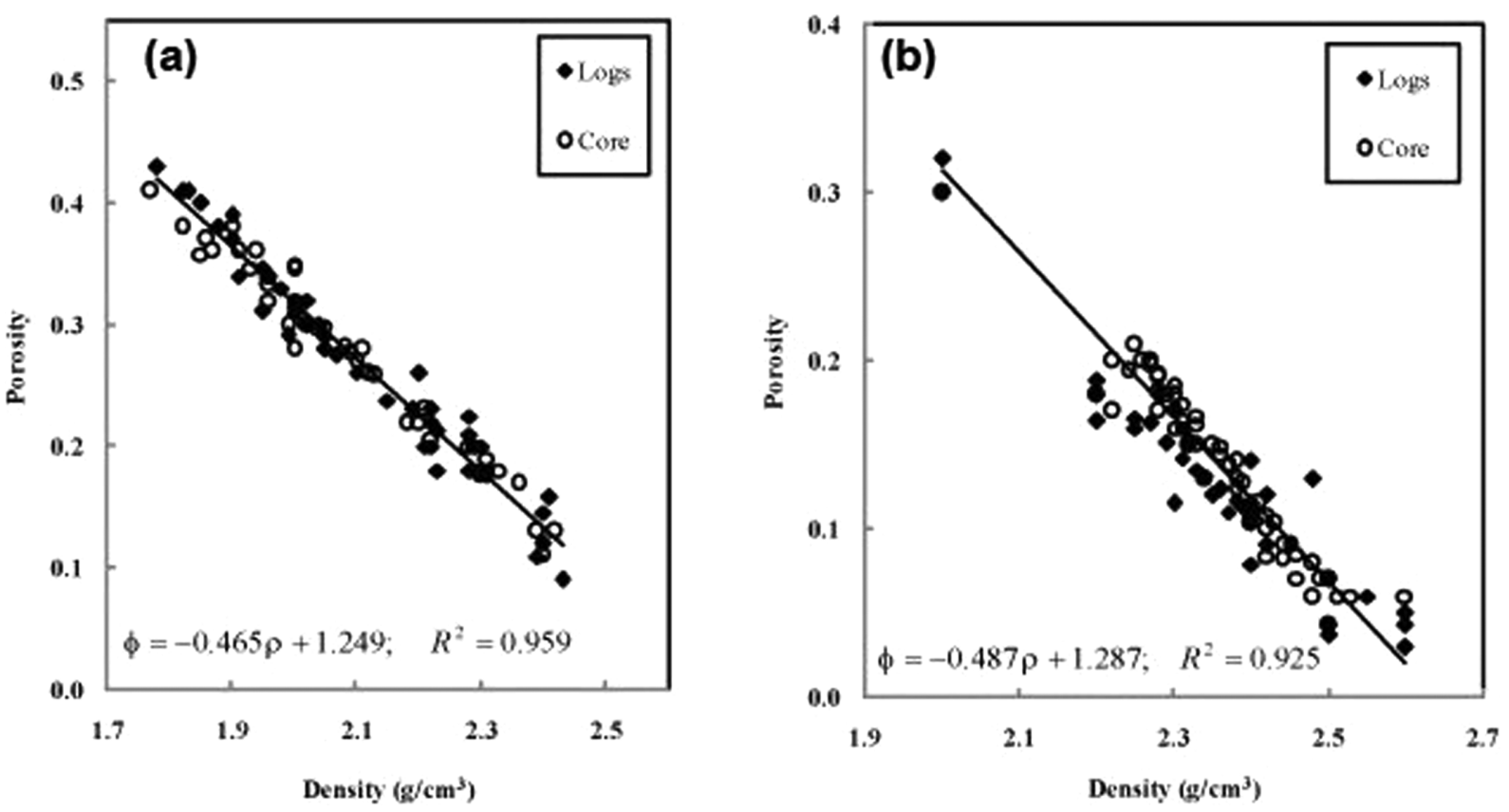

Figure 5. Crossplot between density (log and core) and porosity (log and core) for well A (a) and well B (b).

be determined by least-square regression. The coefficient $m$ represents the gradient in porosity with respect to density. Log and core porosities decrease with increase in density, thus a linear relationship exists between porosities and densities of Datta sandstone. A very close agreement exists between $\log$ porosity and $\log$ density and core porosity and core density with 0.96 regression coefficient $\left(R^{2}\right)$ value in well $A$ (Fig. 5a). In well $\mathrm{B}, \log$ porosity and $\log$ density and core porosity and core density are fairly close to each other with $\mathrm{R}^{2} \sim 0.925$ (Fig. $5 b)$. The average porosity value in the selected interval for well $A$ is $30 \%$ and for well B is $25 \%$. The lower values of porosity in well B are due to reservoir depth and overburden pressure. This decrease resulted mainly from rearrangement of grains during burial. The permeability of sandstone encountered in both wells is crossplotted with porosity (Fig. 6). The permeability shows higher values against higher porosities, which indicates that the reservoir sandstone is highly per-

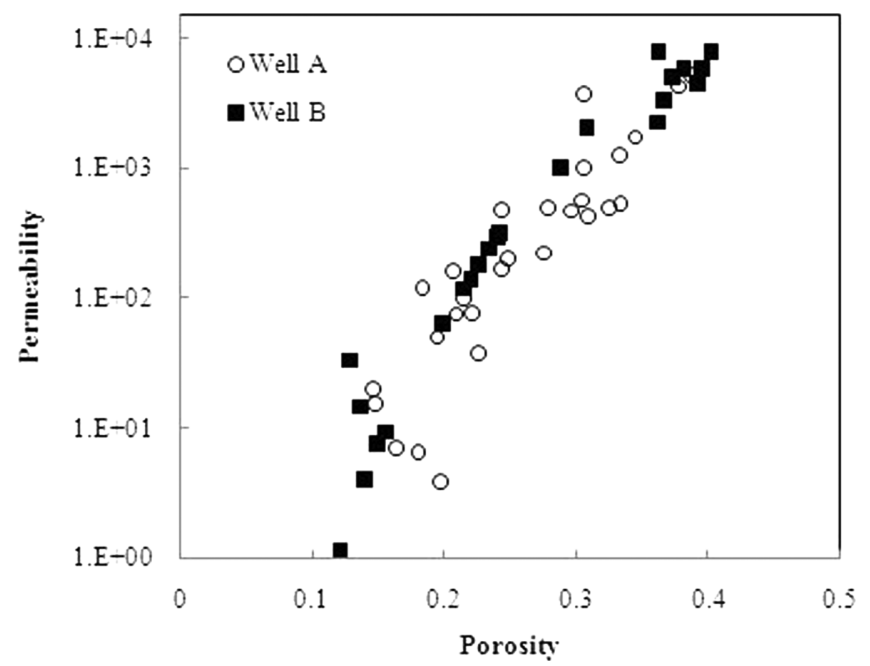

Figure 6. Porosity and permeability cross plot for well A and well B. meable. Thus the pore fluids or hydrocarbon can easily move within the pores.

\section{Water-saturation Uncertainty}

The fluid saturation of a reservoir is basically the amount of all fluids present into the pores. Generally, hydrocarbon (oil/gas) and water are present into the pore spaces. The water saturation $\left(S_{w}\right)$ therefore is the portion of pore volume filled by formation water. The $S_{w}$ determination is the main objective of both core analysis and borehole log interpretations. Decisions regarding the commercial production of oil or gas from a reservoir interval mainly depend on the formation water saturation. Thus the accurate measurement of water saturation is important. Uncertainty analysis was done on the core samples to find out the influence of each parameter on $S_{w}$. The value of $m$ had much more influence than other parameters. Archie proposed $a=1.0$ and $m$ $=1.8-2.0$ for his data set. However, in our case the values of $a$ and $m$ for Datta sandstone are 0.65 and 2.1 respectively. These values are computed by regression analysis of core porosity and formation resistivity factor. The water saturation computed by the resistivity logs in $\mathrm{A}$ and B wells is plotted in Figure 7 against depth. $S_{w}$ in well A are slightly higher than of well B.

\section{Rock Physics Parameters}

The results of rock physics analysis is calibrated at well localities, by comparing the velocity and density estimated from FSM (Eqs. 6 and 10) with the velocity and density from the recorded logs (sonic and density respectively) in the borehole.

Log and core derived petrophysical parameters obtained at in-situ conditions of pore pressure, water saturation, volume of shale, temperature etc. utilized in rock physics modeling as essential ingredients. FSM is applied under the assumption of homogenous distribution 

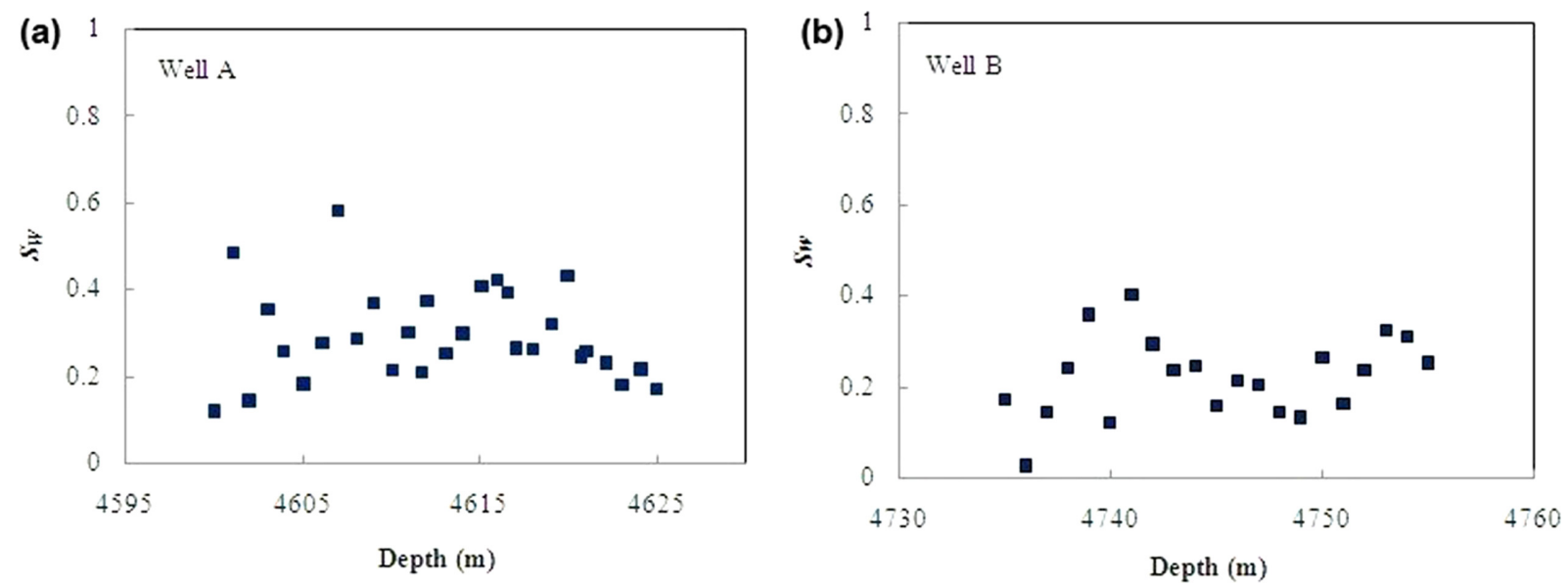

Figure 7. Water saturation in well $A$ (a) and $B(b)$.

Table 1. Reservoir parameters used in FSM

\begin{tabular}{|c|c|c|}
\hline & Well A & Well B \\
\hline Reservoir interval & $4600-4630 \mathrm{~m}$ & $4705-4760 \mathrm{~m}$ \\
\hline Average reservoir temperature $(\mathrm{K})$ & 404 & 409 \\
\hline Average effective pressure (MPa) & 40 & 40 \\
\hline \multicolumn{3}{|l|}{ Fluid parameters } \\
\hline Oil API & 34 & 34 \\
\hline In-situ oil density $\left(\mathrm{g} / \mathrm{cm}^{3}\right)$ & 0.8855 & 0.874 \\
\hline Gas to oil ratio (Litre/litre) & 288.102 & 271.15 \\
\hline Bulk modulus of oil (GPa) & 1.4711 & 1.2942 \\
\hline In-situ density of brine $\left(\mathrm{g} / \mathrm{cm}^{3}\right)$ & 1.181 & 1.169 \\
\hline Bulk modulus of brine (GPa) & 2.095 & 2.11 \\
\hline \multicolumn{3}{|l|}{ Rock parameters } \\
\hline Bulk modulus of Quartz (GPa) & 37 & 37 \\
\hline Bulk modulus of Clay (GPa) & 21 & 21 \\
\hline Density of Quartz $\left(\mathrm{g} / \mathrm{cm}^{3}\right)$ & 2.65 & 2.65 \\
\hline Density of Clay $\left(\mathrm{g} / \mathrm{cm}^{3}\right)$ & 2.58 & 2.58 \\
\hline
\end{tabular}

of fluids within the pores. The applied FSM requires the following input data: pore fluid and matrix properties, reservoir temperature and pressure. Fluid parameters and reservoir condition information are generally available from pressure-volume-temperature (PVT) analysis and well tests measurements, whereas solid-phase properties are inferred from core mineralogical analysis. The parameters used as input for fluid substitution modeling (FSM) are given in Table 1.

Significant predictive relationships are found between porosity and seismic parameters (density, velocities, and acoustic impedance, bulk and shear moduli) of Datta sandstone. The seismic velocities derived from sonic log are compared with the velocities estimated by FSM for both wells A and B are shown in Figures $8 \mathrm{a}$ and $\mathrm{b}$ respectively. As expected, P-wave velocity $\left(V_{P}\right)$ shows good correlations with porosity. The P-wave velocities $\left(V_{P}\right)$ derived from sonic $\log (\mathrm{DT})$ are in very similar to those estimated by FSM with small error (Fig. 8c). The bulk modulus derived from wireline logs by using Equation (11) is compared with $K_{\text {sat }}$ of FSM by using Equation (1) against porosity values for both wells A and B (Figs. 9a and b). For wireline log based $K_{\text {sat }}$, the input P-wave velocity, density and shear modulus are those extracted from sonic, density and shear logs respectively. The relationship in studied wells with strong correlation coefficient is found.
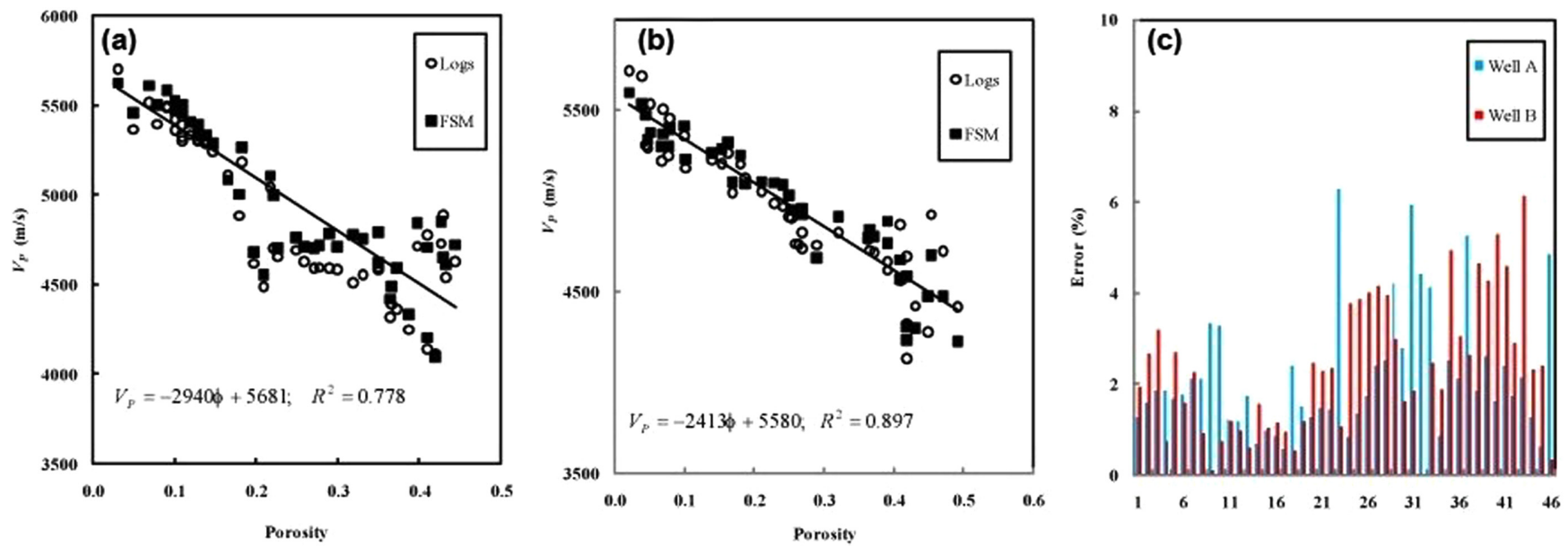

Figure 8. Log derived compressional wave velocity $\left(V_{P}\right)$ and fluid substitution model velocity as a function of porosity in well $A(a)$ and well $B$ (b). (c) Percentage error in log derived $V_{P}$ and FSM derived $V_{P}$ in both wells. 

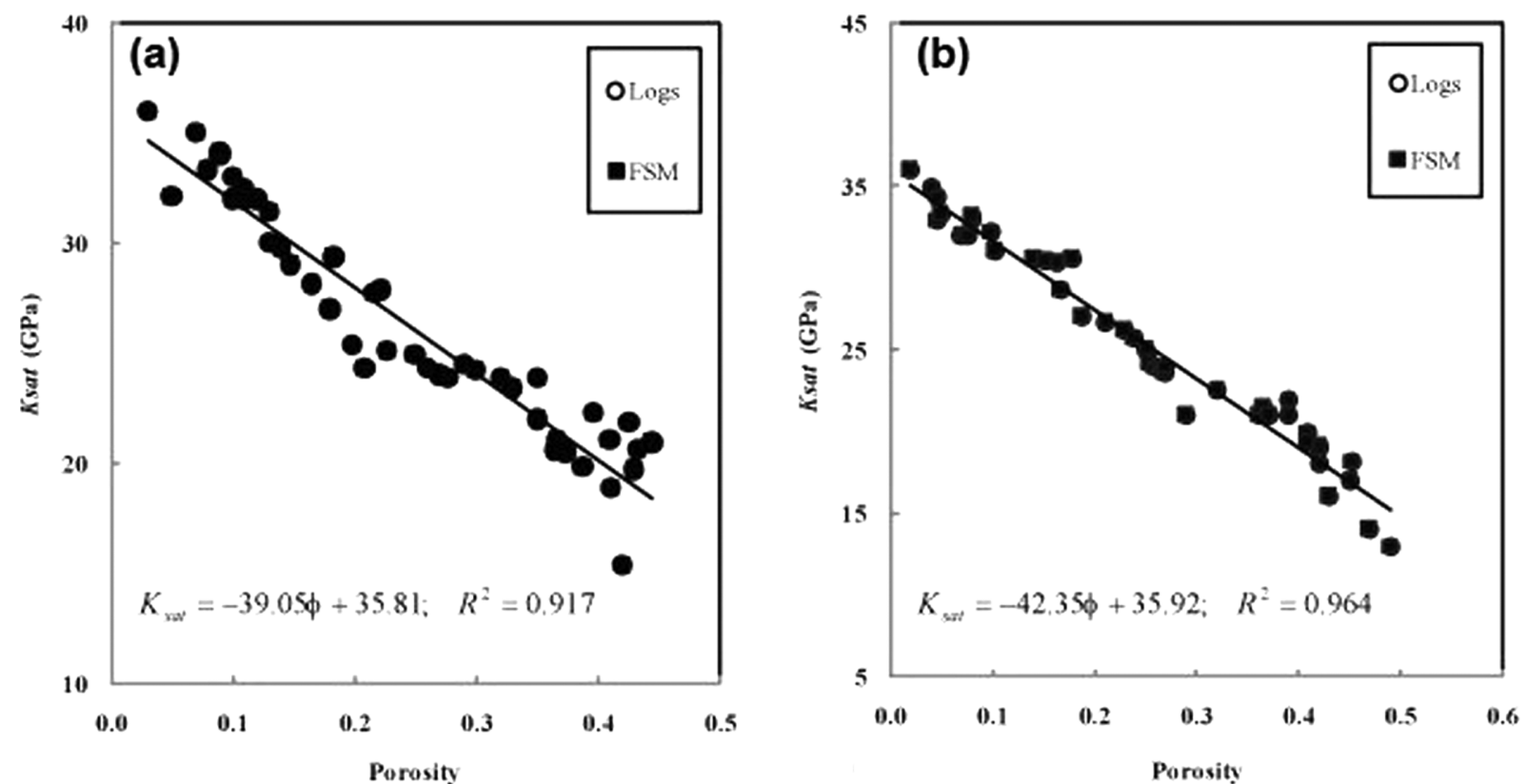

Figure 9. Bulk modulus of rock-fluid composite ( $K_{\text {sad }}$ derived from logs and from fluid substitution model as a function of porosity in well $A$ (a) and well B (b).

\section{Discussion}

The determination of accuracy in reservoir parameters prediction is an important step in formation evaluation. Although some workers has been addressed the uncertainty in geophysical inverse problems (Jackson, 1979; Tarantola, 2005), but it is generally ignored in formation evaluation. In this work, the proposed methodology to reduce uncertainty in reservoir parameters is successfully applied on two wells. The uncertainty analysis was performed at the well location by integrating wireline logs, core plugs and rock physics modeling by means of a statistical approach. The real field data including wireline logs and core plugs from an oil field in the western Potwar geological province was used to estimate reservoir properties and rock physics modeling.

A sequence of equations for the prediction of reservoir parameters of Jurassic Datta sandstone is developed by correlating wireline logs calculations with core measurements. A relationship, based on regression analysis, is proposed to estimate shale volume $\left(V_{s h}\right)$ with the help of gamma ray index (see Fig. 4c). The average values of shale volume in well A were ranged from $14-18 \%$ which converted to volume of sand $82-86 \%$. In well B, the average value of volume of shale is $6-$ $8 \%$ support that reservoir consist of clean sand dominating lithology. The shale values in the well B are sufficiently low to allow free flow of hydrocarbon and effect of water saturation $\left(S_{w}\right)$ and clay bound water is low in the reservoir interval. The density log (RHOB) was taken to calculate reservoir porosity, and compared it with the core plugs measurements (Figs. 5a and b). From the figures it is clear that porosity from core-plugs or logs is decreasing with increase in density, thus showing a non-linear trend. In the same type of rock, density increases due to increase in compaction and reduction in pore spaces. Thus a non-linear trend of density with porosity either core-plugs or $\log$ exists. Porosity is decreasing with increase in density in both wells in whole interval of sand reservoir. The average porosity values in sandstone intervals are $26 \%$ and $30 \%$ in well A and well B respectively. Similar observation of porosity value was made by Khalid et al. (2015) in Datta sandstones of Western Potwar area. The average permeability of these intervals ranges from $650 \mathrm{md}$ to $989 \mathrm{md}$ shows that the reservoir is highly permeable with excellent potential of hydrocarbon accumulation. These average porosity and permeability are good to permit hydrocarbon to flow freely. The average water saturation in well A is 0.29 and in well B it is 0.21 , thus the high saturation of hydrocarbon. Average hydrocarbon movability index in both wells is form $0.23-0.31$ indicate that hydrocarbon is moveable. It is worth mentioning that the methodology adopted in this work is the integration of the rock physics modeling and petrophysical analysis. The rock physics modeling is based on the elastic model (Gassmann fluid substitution) and its isotropic form is used by considering homogeneous, linear and elastic material. Brown and Korringa (1975) extend the Gassmann's model to anisotropic reservoirs. The basic assumptions for the rock physics model used in this work includes: composite rock unit is macroscopically isotropic, pores are communicated, pore must be filled with frictionless fluids and does not interact with rock matrix to soften and harden the fram. The main advantage of this integration is to link between elastic and petrophysical properties of the rock-fluid composite, which reduced the uncertainty in reservoir properties prediction. Since the objective of this study is to reduce the uncertainty in petrophysical parameters of a reservoir. Rock physics parameters can be derived from petrophysical analysis such as density, elastic moduli of rock-fluid composite, velocities etc. Similarly, petrophyscial parameters can also be inferred from rock physics models e.g., porosity, density of formation fluid, fluid modulus, fluid saturation etc. The purpose of integration of rock physics modeling and petrophysical analysis is to enhance the accuracy in the computation of these parameters. Sonic logs can be used as well for prediction, instead of rock physics modeling. However, sometimes the correla- 
tion between sonic logs and petrophysical values is not always optimal in well-log analysis. Moreover, the resolution of sonic travel time $\operatorname{logs}$ is generally poor than the resolving power of geophysical well logs used in reservoir characterization and formation evaluation analysis. On the other hand, the values of rock physics modeling are in a complete consistent with petroelastic results. The elastic moduli and velocities obtained from the rock physics modeling (Eqs. 3-10). Various rock physics parameters (bulk moduli, velocities etc.) were estimated by using petrophysical parameters such as porosity, density, fluid saturation etc. For instance, sonic log was used to compute Pwave velocity $\left(V_{P}\right)$ in reservoir interval and due to the non-availability of shear log, shear (S-wave) velocity $\left(V_{S}\right)$ is computed using Castagna's well-known formula (Castagna et al., 1985). The compressional waves can travel through the fluids because fluids have bulk modulus (change in volume due to pressure exertion) and compressional velocity, dependent on fluid's density and modulus. In the present study, we have computed the $\mathrm{P}$ wave velocity in the reservoir fluids at in-situ conditions. The $\mathrm{P}$ wave velocities in reservoir fluids (brine/oil) present in wells $A$ and B are $1590 \mathrm{~m} / \mathrm{sec}, 1559 \mathrm{~m} / \mathrm{sec}$ (for brine) and $1350 \mathrm{~m} / \mathrm{sec}$ and $1285 \mathrm{~m} / \mathrm{sec}$ (for oil) respectively. The compressional wave velocity is directly linked with the bulk modulus of pore fluids and therefore brine saturated rocks have higher $P$ wave velocities as compared to oil saturated rocks. In order to verify predicted accuracy in results, Figure $8 \mathrm{c}$ displays an error (percentage) analysis for compressional wave (P-wave) velocities, which is $6 \%$ maximum. $V_{P}$ decreases linearly with increase in porosity in both wells. The $\mathrm{P}$-wave velocities obtained in well A lie in the range of $4140-5320 \mathrm{~m} / \mathrm{s}$ whereas in well B are in the range of $4205-5340 \mathrm{~m} / \mathrm{s}$. This difference in velocity values, which has been even detected in one rock type with similar porosity, is may be due to different factors like burial depth, number of openings, orientation of cracks, type and pressure of fluids in pore spaces. The $\mathrm{P}$ and $\mathrm{S}$ wave velocities are strongly dependent on burial depth, the increase in burial depth results in high compaction and finally an increase in $\mathrm{P}$ wave velocities. In well $\mathrm{B}$, reservoir sand is located at comparatively higher depth and therefore has higher $\mathrm{P}$ wave velocity. Reservoir porosity (number of openings) and velocities are inversely related to each other and reservoir porosity varies spatially and vertically due clay content, grain sorting and deposition process. P wave velocity is also affected due to pore fluid types and their saturation levels. Due to lower modulus of gas, the water saturated rocks are always having higher $V_{P}$ as compared to gas saturated rocks. The pressure of fluids present with the pores (pore pressure) has inverse relation with seismic compressional velocities and high pressure zones show reduced velocities. Similarly, orientation of cracks also affects the $\mathrm{P}$ wave velocity and seismic velocities have less travel time when travel along the direction of cracks and vice versa.

\section{Conclusions}

An integrated approach to estimate reservoir parameters and formation evaluation is very effective to minimize the error in these measurements. In this work, a workflow with the help of statistical analysis is proposed to find out reservoir parameters from geophysical well logs and core samples with large accuracy. The mean values of volume of shale $\left(V_{s h}\right)$ in these wells are relatively low, which show that the reser- voir is shaly sands to clean sand grade. The porosity and permeability are high; indicating the quality of reservoir is very good and formation fluid is movable. Linear relationship is found between density and porosity in both wells A and B. The core plugs porosities provide better match with log porosity thus decrease the uncertainty in the measurements. Logs derived velocities (compressional or P-wave) are in very close agreement to those estimated from rock physics (fluid substitution modeling) analysis. The P-wave velocities predicted from both wells (A and B) are very alike to each other. These velocities were presumed because of their closeness and the same interpreted sandstone reservoir. However, $V_{P}$ predicted by rock physics model is somewhat higher than derived from sonic logs.

\section{References}

Ahmed, N., Khalid, P., Shafi, H.M.B., and Connolly, P., 2017, DHIs evaluation by combining rock physics simulation and statistical techniques for fluids identification of Cambrian to Cretaceous clastic reservoirs in Pakistan. Acta Geophysica, v. 65, pp. 991-1007.

Archie, G.E., 1942, The electrical resistivity $\log$ as an aid in determining some reservoir characteristics. Transactions of the American Institute of Mechanical Engineering, v. 146, pp. 54-62.

Barton, E.D., Aristegui, J., Tett, P., and Navarro-Perez, N., 2004, Variability in the Canary Islands area of filament-eddy exchanges. Progress in Oceanography, v. 62, pp. 71-94.

Batzle, M.L., and Wang, Z., 1992, Seismic properties of pore fluids. Geophysics, v. 64, pp. 1396-1408.

Biot, M.A. 1941, General theory of three-dimensional consolidation. Journal of Applied Physics, v. 12, pp. 155-164.

Brown, J.S., and Korringa, J., 1975, On the elastic properties of a porous rock on the compressibility of the pore fluid. Geophysics, v. 40, pp. 608-616.

Castagna, J.P., Batzle, M.L., and Eastwood, R.L., 1985, Relationship between compressional wave and shear wave velocities in clastic silicate rocks. Geophysics, v. 50, pp. 571-581.

Domenico, S.N., 1984, Rock lithology and porosity determination from shear and compressional wave velocity. Geophysics, v. 49, pp. 1188 1195.

Clavier, C., Coates, G., and Dumanoir, J., 1984, The Theoretical and Experimental Basis for the 'Dual Water' Model for the Interpretation of Shaly Sands. Society of Petroleum Engineers Journal, v. 24, pp. 153-168.

Fylling, A., 2002, Quantification of petrophysical uncertainty and its effect on in-place volume estimates: Numerous challenges and some solutions. Proceedings of SPE Annual Technical Conference and Exhibition, 2002, Society of Petroleum Engineers, SPE-77637-MS. https://doi.org/10.2118/77637-MS

Gassmann, F., 1951, Uber die Elastizitat poroser Medien: Vierteljahrsschrift der Naturforschenden. Gesellschaft in Zurich, v. 96, pp. 1-23.

Gist, G.A., 1994, Interpretating laboratory velocity measurements in partially gas-saturated rocks. Geophysics, v. 59, pp. 1100-1109.

Grana, D., Pirrone, M., and Mukerji, T., 2012, Quantitative log interpretation and uncertainty propagation of petrophysical properties and facies classification from rock physics modeling and formation evaluation analysis. Geophysics, v. 77, pp. 45-63.

Gupta, S.D., Chatterjee, R., and Farooqui, M.Y., 2012, Rock physics template (RPT) analysis of well logs and seismic data for lithology and fluid classification in Cambay Basin. International Journal of Earth Sciences, v. 101, pp. 1407-1426.

Han, D.H., Nur, A., and Morgan, S., 1986, Effects of porosity and clay content on wave velocities in sandstones. Geophysics, v. 51, pp. 2093 2107. 
Han, D., and Batzle, M., 2002, Fizz water and low gas-saturated reservoirs. The Leading Edge, v. 21, pp. 395-398.

Heidari, Z., Torres-Verdin, C., and Preeg, W.E., 2010, Improved estimation of mineral and fluid volumetric concentrations in thinly-bedded and invaded formations. Proceedings of the $51^{\text {th }}$ Annual Logging Symposium, 2010, Society of Petrophysicists and Well Log Analysts, pp. $1-16$.

Hilterman, F., 2001, Seismic amplitude interpretation. SEG distinguished instructor short course, Society of Exploration Geophysicists, Tulsa.

Jackson, D.D., 1979, The use of a priori data to resolve non-uniqueness in linear inversion. Geophysical Journal of the Royal Astronomical Society, v. 57, pp. 137-157.

Khalid, P., Broseta, D. Nichita, D.V., and Blanco, J., 2014, A modified rock physics model for analysis of seismic signatures of low gas-saturated rocks. Arabian Journal of Geosciences, v. 7, pp. 3281-3295.

Khalid, P., and Ghazi, S., 2013, Discrimination of fizz water and gas reservoir by AVO analysis: a modified approach. Acta Geodaetica et Geophysica, v. 48, pp. 347-361.

Khalid, P., Yasin, Q., Sohail, G.M.D., and Kashif, J.M., 2015, Integrating core and wireline log data to evaluate porosity of Jurassic formations of Injra-1 and Nuryal-2 wells, Western Potwar, Pakistan. Journal of Geological Society of India, v. 86, pp. 553-562.

Kuster, G.T., and Toksöz, M.N., 1974, Velocity and attenuation of seismic waves in two-phase media: Part I. theoretical formulations. Geophysics, v. 39, pp. 587-606.

Larionov, V.V., 1969, Radiometry of boreholes (in Russian). NEDRA, Moscow.

Mavko, G., Mukerji, T., and Dvorkin, J., 2009, The Rock Physics Handbook. Cambridge University Press, Cambridge, $246 \mathrm{p}$.

Mukerji, T., Jorstad, A., Avseth, P., Mavko, G., and Granli, J.R., 2001, Mapping lithofacies and pore-fluid probabilities in a North Sea reservoir: seismic inversions and statistical rock physics. Geophysics, v. 66, pp. 988-1001.

Murphy, W., Reischer, A., and Hsu, K., 1993, Modulus decomposition of compressional and shear velocities in sand bodies. Geophysics, v. 58, pp. 227-239.

Pride, S.R., Berryman, J.G., and Harris, J.M., 2004, Seismic attenuation due to wave induced flow. Journal of Geophysical research, v. 109. DOI: 10.1029/2003JB002639

Russell, B.H., Hedlin, K. Hilterman, F.J., and Lines, L.R., 2003, Fluidproperty discrimination with AVO: a Biot-Gassmann perspective. Geophysics, v. 68, pp. 29-39.

Stieber, S.J., 1970, Pulsed neutron capture log evaluation - Louisiana Gulf Coast. Proceedings of Fall Meeting of the Society of Petroleum Engineers of AIME, 1970, Society of Petroleum Engineers, SPE 2961. https://doi.org/10.2118/2961-MS

Taib, D., and Donaldson, E.C., 2004, Petrophysics: Theory and Practice of Measuring reservoir Rock and Fluid Transport Properties. Elsevier, Burlington, $458 \mathrm{p}$.

Tao, G., and King, M.S., 1993, Porosity and pore structure from acoustic well logging data. Geophysical Prospecting, v. 41, pp. 435-451.

Tarantola, A., 2005, Inverse Problem Theory. Society of Industrial and Applied Mathematics, $324 \mathrm{p}$.

Viberti, D., 2010, A rigorous mathematical approach for petrophysical estimation. American Journal of Applied Sciences, v. 7, pp. 1509-1516.

Winkler, K.W., and Murphy III, W.F., 1995, Acoustic velocity and attenuation in porous rocks. In: Ahrens, T.J. (Ed.), Rock Physics and Phase Relations: A Handbook of Physical Constants. American Geophysical Union, pp. 20-34.

Wyllie, M.R.J., Gregory, A.R., and Gardner, L.W., 1956, Elastic wave velocities in heterogeneous and porous media. Geophysics, v. 21, pp.
41-70.

Zinszner, B., and Pellerin, F.M., 2007, A Geoscientist's Guide to Petrophysics. Technip, Paris, $61 \mathrm{p}$.

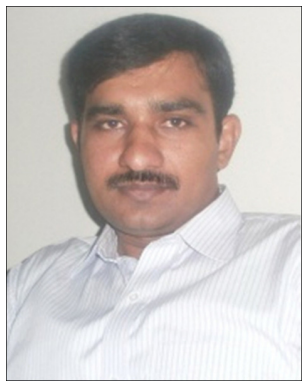

Perveiz Khalid is currently working as Assistant Professor and Head of Geophysics at the Institute of Geology, University of the Punjab, Lahore. In 2011, he received his Ph.D. degree in Geophysics from University of Pau, France. He is an active and dynamic researcher. More than 50 internationally peer-reviewed publications are on his credit. He presented his research work in more than 40 international conferences. His research interests are rock physics modeling, exploration geophysics, hydrogeophysics and seismic hazard assessment.

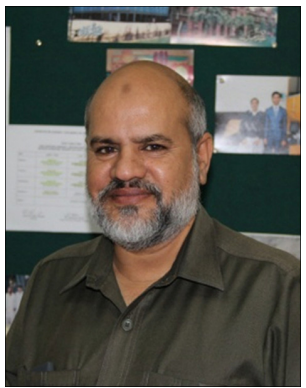

Zia $\boldsymbol{U d}$ Din is working as Assistant Professor at the Institute of Geology. He holds M.Phil. in Geophysics degree from the University of the Punjab. He is author of various national and international publications. His areas of interests are exploration geophysics, shallow subsurface and earthquake seismology.

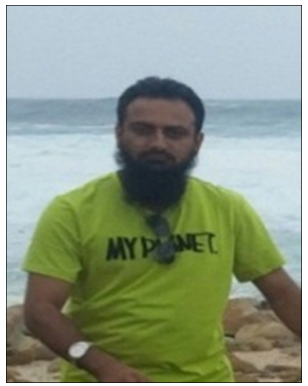

Nisar Ahmed is currently working as Lecturer (Geophysics) at Institute of Geology, University of the Punjab, Pakistan. His fields of expertise are reservoir-geophysics, rockphysics, petrophysics, reservoir geomechanics and seismic interpretation. In respect of his academic qualification, Mr. Ahmed has done his M.Sc. in applied geology in 2009 and M.Phil degree (geophysics) in 2013 from Institute of Geology, University of the Punjab. Currently, he is also doing his Ph.D. research under the entitlement 'Numerical Simulation of Upscaling Effects due to Wave Induced Fluid Flow (WIFF) in Poro-thermoelastic Media'. His research contribution includes 16 peer-reviewed articles and participation in 32 national and international scientific conferences.

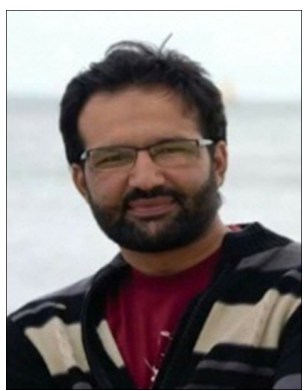

Malik M. Saad Missen is working Assistant Professor in Dept of Computer Science of Islamia Univ of Bahawalpur. He completed his $\mathrm{PhD}$ from Univ of Toulouse France in 2011. His areas of research include Geographical Information Retrieval, Document Image Analysis ans Online Social Media mining amd analysis. 